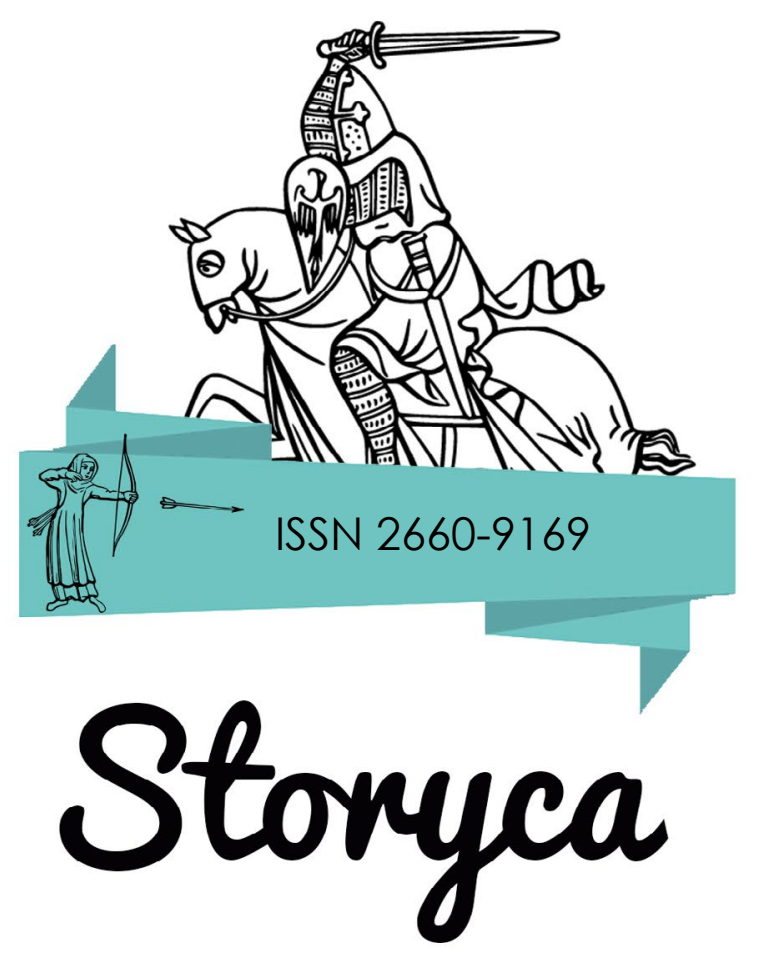

\title{
30 años de La Crónica de Leodegundo: aproximación a la gran saga de la historieta histórica española
}

Jacobo Hernándo Morejón

Universidad de Málaga

\section{Introducción}

A la hora de pensar en historia y cómic durante los últimos años parece que la atención y el rápido pensamiento se derivan hacia el periodo del siglo $\mathrm{XX}$, en el que la memoria histórica se ha resguardado y hecho fuerte. Aunque no es difícil entender el conjunto de circunstancias que han influenciado y permitido una gran expansión y presencia de las publicaciones de cómics sobre historia contemporánea, parece que ha eclipsado casi por completo cualquier otro movimiento editorial en otras áreas. No solo eso, sino que, en el periodo de mayor aparición de títulos en las estanterías y de estudios sobre cómic, parece que la historia en sí misma, o al menos toda aquella historia que se extiende más allá de 1900, ha quedado relegada a un segundo o incluso tercer lugar en comparación al siglo $X X$ y el resto de géneros de la historieta.

No puede ser entendido, por tanto, que, cuando se consultan aquellos manifiestos 
hacia la defensa del cómic, de su vigencia como sujeto de investigación, de la necesidad de su introducción en los espacios públicos y culturales como los museos o la universidad, se tienda olvidar que uno de los hechos más importantes en la normalización del cómic haya sido, precisamente, que una universidad pública haya tomado el rol de editor de un cómic: La Crónica de Leodegundo (Meana 1991-2006).

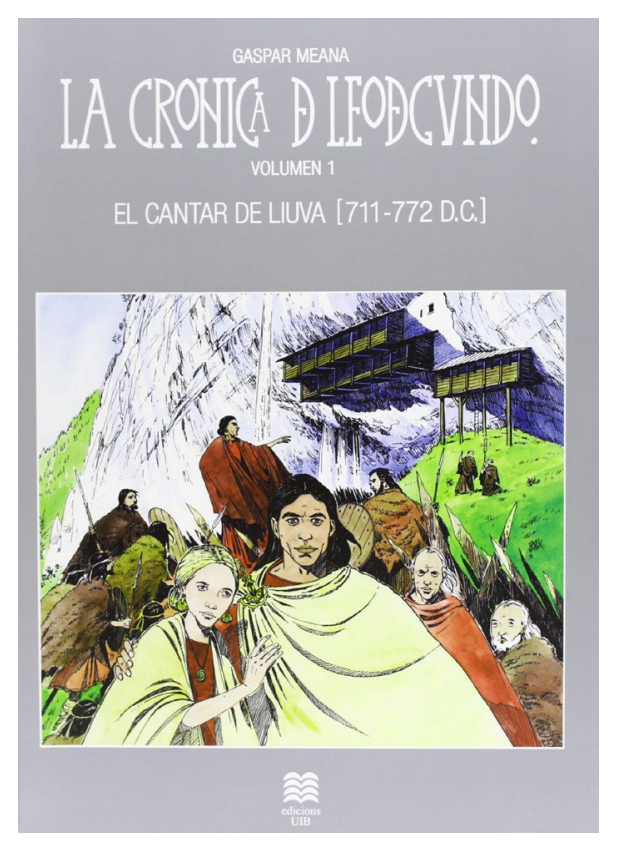

La Crónica de Leodegundo.

El cantar de Liuva (711-772 d. C.), Gaspar Meana

Si bien se trata de una reedición y no de una nueva publicación, lo cierto es que no se trata de un cómic al uso en el sentido de que es un único álbum. La Crónica consta de 25 volúmenes que la Universitat de les Illes Balears se encargó de traducir del bable y reeditar por primera vez en castellano y catalán en 5 grandes volúmenes integrales (Meana 2013-2016). Una tarea nada fácil que exige un gran esfuerzo económico debido al coste que requiere la impresión de cómics en comparación a aquella tradicional de los libros de texto.

Pese a que ha tenido poca notoriedad la vida editorial de este cómic, no así entre el público más especializado el propio título, cuyo contenido ha sido comentado por algunos estudiosos del cómic a través de los años. Aunque conocido en Asturias, lugar de origen y en cuyo idioma, el bable, estuvo publicado originalmente, es más comprensible que sea menos famoso en el resto de España. La primera mención que hemos conseguido encontrar relativa a la obra procede del libro de lectura básica de Sergi Vich La historia en los cómics (1997: 70-71) cuando la serie ya llevaba poco más de la mitad de sus volúmenes totales publicada. Pese a que formaba parte de un conjunto de comentarios amplísimo, tan amplio que hace que el valor de sus palabras quede quizás asfixiado y tomado como un mero apunte más, la alabanza al trabajo de Meana es palpable, resaltando la labor de documentación bibliográfica y consulta metódica con los estudios publicados más recientes para poder crear desde la mayor fidelidad posible La Crónica.

Podemos encontrar otro apunte en el libro Asturias: imágenes de historieta y realidades regionales (Fernández, 1999: 24-26), donde se la señala como la mejor representante de la historieta histórica asturiana y se afirma que su mayor virtud es la combinación entre la épica histórica con la vida cotidiana y privada sin lastrar un relato de visualización cinematográfica.

Hasta la fecha el espacio de mayor atención introspectiva dedicado a Gaspar Meana, y por extensión a sus obras, es el capítulo dedicado por Faustino Rodríguez Arbesú en su La Historieta Asturiana (2002: 53-69), texto indispensable para conocer al autor y sus circunstancias, cómo procede a elaborar su trabajo y la forma en que debe asumirse su lectura. Para nuestro pesar, sigue teniendo una triste vigencia la afirmación de Rodríguez cuando comenta que estamos 
ante uno de los autores españoles que más ha publicado y que menos es conocido en España.

Le sigue, pocos años después, Fernando Galván Freile (2008) en su artículo «La imagen de la Edad Media en el cómic». Pese a que sigue las pautas de reconocer o etiquetar La Crónica como una obra enfocada en la historia del reino astur y alabar, de nuevo, la ambientación desarrollada en sus viñetas, acaba señalando que existen anacronismos y excusa en la carencia de documentación la invención de ciertos tipos de recreación asociados a los ambientes cotidianos de los individuos.

Vamos a volver con uno de los autores anteriormente mencionados en nuestro discurso diacrónico de referencias sobre crítica de cómic. Sergi Vich volverá a centrar su atención sobre La Crónica en 2013, en el marco de un artículo para la revista Arqueología, historia y viajes sobre el mundo medieval (2013: 34-45), donde dedicará la página final de su texto íntegramente a la obra que es objeto de nuestro interés. Transcurridos unos 16 años desde la publicación de su libro, ya con la serie concluida y el tiempo y la distancia para una reflexión apropiada, Vich se confiesa ante un dilema acerca de cómo plantear una explicación que permita clasificar un cómic como La Crónica de Leodegundo: si como un cómic de ficción con base histórica o una tesis histórica expresada mediante viñetas (2013: 45). En cualquier caso, Vich logra identificar con éxito una de las tesis principales de Gaspar Meana, así como el apoyo e inspiración en la obra de Claudio Sánchez Albornoz en la génesis del cómic.

Una de las últimas adiciones bibliográficas a esta lista la encontramos bajo la firma de María del Mar Díaz González (2021: 189-201). Aunque enmarcado en el mismo trabajo panorámico sobre la producción historietística asturiana, la autora toma espacio específico en su texto para aproximarse a La Crónica y desgranar sus contenidos, si bien su discurso se ve marcados por algunos errores de base al confundir nombres y número de personajes protagonistas, sentido de la trama o incluso algunos detalles que ponen de manifiesto que su conocimiento sobre la serie es, no ya limitado, sino sumamente superficial debido a la torpeza a la hora de abordar ciertas expresiones. Alaba, como no podía ser de otra manera, la labor de documentación, investigación y recreación del contenido del cómic e identifica otra de las tesis de la obra no antes mencionada por autores anteriores: la conexión del reino de Asturias con el imperio carolingio y, por tanto, la puesta en duda del aislamiento político en la franja cantábrica de su monarquía.

Nos encontramos por tanto ante una misma pauta historiográfica: La Crónica

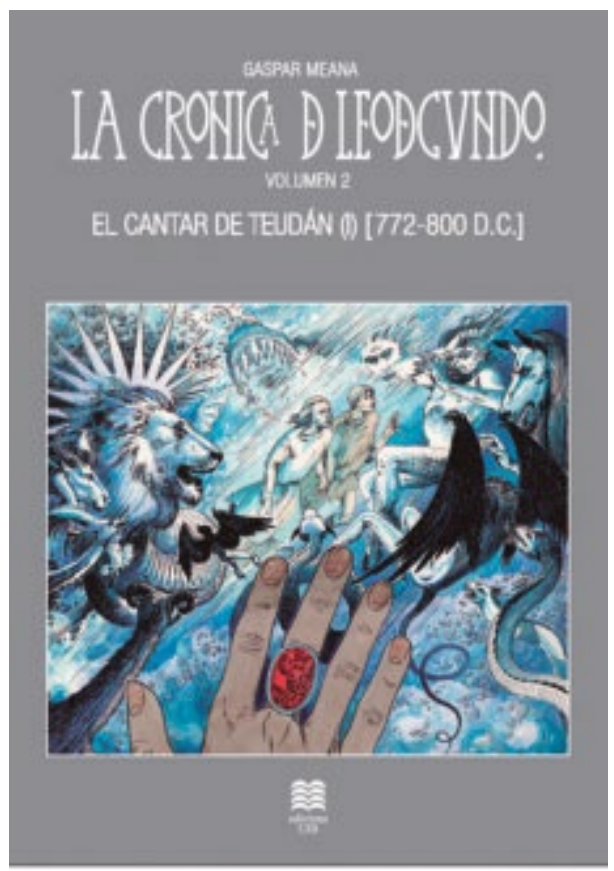

La Crónica de Leodegundo. El cantar de Teudán (I) (772-800 d. C.) Gaspar Meana 
de Leodegundo es conocida y es leída, a ciencia cierta al menos entre apasionados de la temática histórica, pero carece de labores de análisis crítico extenso o monográfico por parte de investigadores del mundo del cómic o académico en general. Tal vez sea Galván Freile quien da una pista acerca de por qué puede explicarse tal carencia al saber percibir que era una publicación de gran interés desde múltiples aspectos (2008: 136), lo que hace necesario un esfuerzo multidisciplinar para lograr desgranar la gran carga de elementos presentes de la Alta Edad Media.

Otras referencias secundarias que dan testigo del alcance de la obra pueden ser la que tiene en La pintura en el cómic (Gasca y Mensuro, 2014: 96), que toma el uso de una miniatura de beato en una de sus portadas que, si bien exacta, se siente insuficiente ante la aparición de más ejemplos de artes visuales susceptibles de ser incluidos en el contenido del libro. Tampoco debemos pasar por alto el hecho de que hemos comenzado a hacer uso de los contenidos de las viñetas en otros trabajos no relacionados con la valoración general de la obra como anteriormente (Hernando, 2021: 485-492) e incluso como publicación de referencia como punto de partida de toda una nueva etapa en la periodización de la historia del género (Hernando, 2018: 138).

Por último, aunque hemos visto que se puede localizar la presencia de La Crónica de Leodegundo en los estudios sobre cómic, podemos destacar el hecho no menos importante de que también aparece en investigaciones al margen de los mismos. Estas referencias constituyen otro tipo de reconocimiento y prueba de valía sobre la labor investigadora del autor y su pericia a la hora de arrojar propuestas y teorías sobre determinados elementos concretos que son desplegados a través de los distintos volúmenes. En particular, la primera cita que tenemos en textos académicos tradicionales lo encontramos en un artículo de García de Castro, cuando hace mención y reconoce que la relación entre Alfonso II y su asociación con Jacob se produce, de manera alternativa e independiente, en el cómic de Meana (2003: 160). La segunda referencia la podemos encontrar también en las notas que Borge Cordovilla menciona como fuente a las notas que Meana proporciona en el volumen XXIII (2005: 51-55) en el que teoriza una nueva significación simbólica para el conjunto palaciego del entorno del Naranco (2017: 179).

Con todas estas noticias que hemos recogido, vamos a intentar ofrecer una aproximación panorámica para poder medir la monumental obra que es La Crónica de Leodegundo. Para ello vamos a recurrir al conjunto de preguntas que Armando Petrucci formulara acerca de cómo trabajar documentos según la metodología de la historia de la cultura escrita (2002: 8). El motivo no es solo porque creemos en la validez del conjunto de cuestiones empleadas para obtener respuestas sobre cualquier tipo de documento legible, sino porque también la propia obra impele a un acercamiento desde la disciplina de las Ciencias y Técnicas Historiográficas por la gran cantidad de detalles e informaciones que se pueden localizar y extraer tanto directa como indirectamente de sus viñetas. 


\section{Análisis de la obra}

\section{1. ¿Quién lo realizó?}

Comenzando por la cuestión más necesaria de responder primero, hay que conocer al autor. Gaspar Meana González (Gijón, 1960) rechazó los deseos de su familia, de limitados recursos económicos, para que se dedicara a estudiar Derecho en la universidad, abandonando la carrera y formándose en la Escuela de Artes Aplicadas de Oviedo persiguiendo lo que le hacía ser feliz. Egresado de Dibujo Publicitario y Diseño Gráfico en 1988, se vio en el paro poco después y, tomando la misma resolución que el escritor Frederyk Forshyte tuvo cuando se halló en la misma condición, se lanzó en 1989 a crear La Crónica de Leodegundo, que no fue publicada hasta que se había terminado el quinto volumen. Gran apasionado de la fantasía épica pero aún más de la historia, cualquiera podría decir que era un candidato perfecto para ingresar en la carrera de Historia, pero económicamente era inviable y, a decir del autor, los catedráticos no iban a ser flexibles a sus ideas, ni tampoco se sentía seguro de compartirlas con ellos, quienes podían rentabilizarlas a su costa (Meana, 2014: 228).

Lo cierto es que Gaspar Meana ha sabido ganarse la vida como dibujante e ilustrador profesional, siendo reconocido con premios a su trabajo pero, más importante, siendo designado para elaborar distintos encargos gráficos para abordar Cangas de Onís en la historia, en 1997, por parte del Consistorio del concejo, y, por designio del Gobierno del Principado de Asturias, el pequeño cómic de El reino que nació en Asturias, donde se ve reconocida en una publicación oficial y gubernamental su teoría de que Ramiro I usurpó el trono a Nepociano (Meana, 2018: 5), aunque no así su propuesta cronológica de cómo ocurrieron los acontecimientos (Meana, 2016: 59-65). Estas oportunidades laborales le han permitido que los personajes de La Crónica de Leodegundo se prodiguen por estas publicaciones de origen institucional y le da, en cierta manera, un sentido

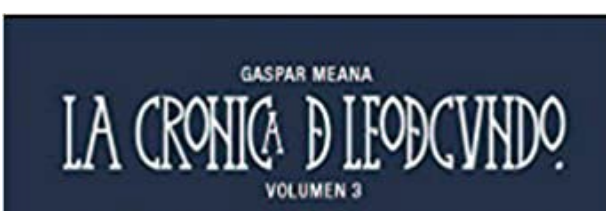

E CANTAR DE TEUDAN (II) [800-814 D.C.]

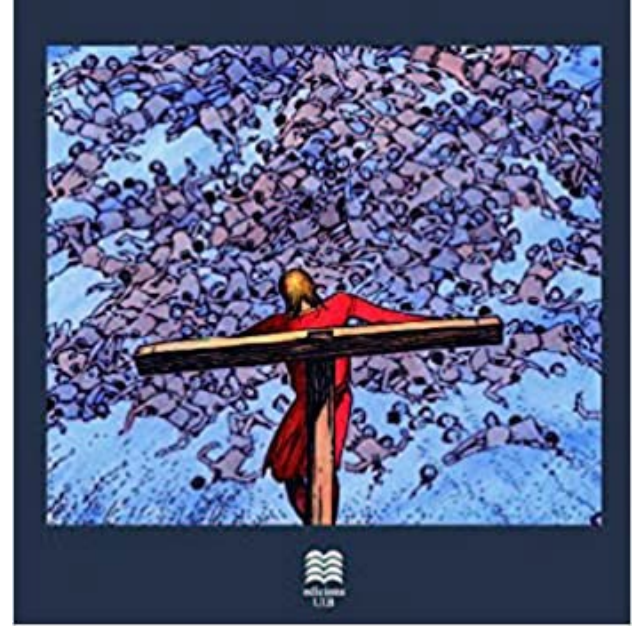

La Crónica de Leodegundo. El cantar de Teudán (II) (800-814 d. C.), Gaspar Meana conceptual de uuniverso compartido» entre sus obras y refrenda su posición honorífica como cronista de Asturias.

Como documentalista, demuestra una gran capacidad de síntesis y amplios conocimientos sobre los hechos que acontecieron entre el 711 y el $960 \mathrm{~d}$. C. Hilvana con sobrada soltura una historia repleta de guiños, de anécdotas, dramas humanos y observación de hasta los mínimos detalles aportados no 
solo por las fuentes medievales, sino también por la historiografía y arqueología contemporánea, de la que no dejó de consultar para estar constantemente actualizado y mejorar su formación autodidacta. Este afán por reflejar los últimos resultados de las investigaciones más punteras le ha hecho desear poder rehacer los primeros 5 álbumes de la serie (Meana, 2014: 225-226).

El otro gran protagonista del que podríamos hablar casi como una persona segregada de su creador es el monje Leodegundo y su ayudante e hijo Suero (II). Hijo de Oria y Suero (I), fue en su adolescencia espatario de Alfonso III en los últimos años de su reinado. Tras la deposición del rey magno a manos de su hijo García, solamente sabemos que ingresa en el monasterio de Novotelo, fundado por sus padres. El hallazgo de una fíbula visigoda le hace convencerse de la llegada del fin de los días y de que debe hacer justicia a su linaje ultrajado por las antiguas afrentas y manipulación de la historia en las crónicas escritas tras Alfonso II. Con este convencimiento emprende la redacción de su crónica en base a las noticias y cuentos que le fueron transmitidas por las generaciones que le precedieron.

Desafortunadamente fallecerá dejando inconclusa su tarea debido al esfuerzo realizado y es su hijo Suero quien debe terminar los últimos párrafos de la crónica, antes de abandonar Asturias y marchar al sur, hacia Toledo, donde se le perderá la pista a él y a sus descendientes entre la mozarabía de la ciudad.

\section{2. ¿Qué dice el cómic?}

Quizás identificar el contenido del cómic pueda ayudar a solucionar la disyuntiva planteada por Vich en su artículo de 2013. En esencia, aunque se denomine como crónica, técnicamente el documento elaborado por Leodegundo es una genealogía de su ascendencia y la historia de aquellos. El monje, sin embargo, no cubre a todos los miembros de su familia por igual y se restringe únicamente a aquellos que realmente dan lumbre a su línea de sangre. Es notorio el salto que da entre la unión de sus abuelos, pasando de puntillas por el reinado alfonsí, hasta directamente ofrecer su punto de vista como testigo de los últimos días de Oviedo como capital del reino, soslayando por completo el relato de sus padres. Seguramente se deba al desgaste del propio Meana lo que le impulsó a hacer recortes al alcance de su obra.

Es cierto que su relato está íntimamente ligada a la suerte de la dinastía pelágida, con la que están ligados por sangre, y por ello suele ser identificado como un cómic sobre historia del reino astur que, a nuestros ojos, lo es. Pese a que esta es la postura más clásica, la lectura nos enseña que el contenido es una crónica muy parecida a aquellas que ya se han producido como la del 754 o la propia de Alfonso III en el sentido de que la información ofrecida rebosa los bordes geográficos, no ya de la cordilla Cantábrica, sino de la misma Península, gracias a las peripecias vitales que tendrán que vivir y padecer los antepasados sobre los que recae la acción. No es casualidad tampoco que se reflejen los asuntos de Constantinopla, del califato abasí, el emirato Andalusí y Aquisgrán, entrelazándose con algunas historias de índole 
propiamente familiar como el deambular por el Mediterráneo del hijo de Teudán. Gracias a estos viajes se ofrece un punto de interés en las noticias y relatos que traerán de vuelta sobre imperios ricos y ciudades opulentas como Bagdad y se crea una visión caleidoscópica del mundo Mediterráneo. Díaz González identificó correctamente estas relaciones con una de las intenciones del propio monje: para combatir la ausencia de referencias a los francos en las crónicas asturianas.

La trama hace que los personajes se sitúen en primera fila de acontecimientos que son forzados a vivir y permite la digresión en asuntos muy lejanos que, por otra parte, bien podrían ser exageraciones de los propios antepasados o deformaciones producidas durante la transmisión oral (Domínguez, 2011: 38-40). El propio Leodegundo debe viajar para consultar la biblioteca de la catedral de San Salvador de Oviedo para facilitar su tarea solo para descubrir que ha habido una censura y expurgo de aquellos documentos que no servían para la propaganda de los descendientes de Ramiro (Meana, 1997: 3). Es en el Cantar de Teudán, tío-bisabuelo de Leodegundo, precisamente donde más proliferan los asuntos sobrenaturales, al ser un miembro de la familia cuya biografía es transmitida a través de varias personas que tuvieron relación con él y que cuyas aventuras y pagana espiritualidad debieron deformar su imagen real para el monje, sirviéndole de instrumento para mostrar parte de la moraleja de la ruindad del mundo y el individuo.

Porque la moralidad es importante para nuestro ficticio cronista y está presente durante toda la obra, en un acierto por parte de Meana, al imbuir la propia lectura de un aura literaria medieval. Por esto mismo Teudán sufre rasgos que podríamos identificar con la de los caballeros de los mitos artúricos. Al mostrar más interés por los asuntos terrenales se parece a Gawain; por traicionar a su rey acostándose con su amada, es Lanzarote; y por encontrar el Arca Santa, que sirve como trasunto del Grial, ayudando a resarcirse con su señor, obtiene la gloria de Galahad. Algo de lo que el propio Meana da cuenta y tomará ventaja en la construcción de la historia, gracias a lo que comenta en la introducción al volumen 2, editado por la UIB, al repasar las propuestas de Erich von Richtofen sobre la aportación ibérica a la conformación del mito artúrico. No es tampoco casualidad que ya en el final del ciclo dedicado a su inquieto y ambicioso antepasado se proclame que ha terminado una era, la edad de los sueños, con la destrucción de Bagdad y la pérdida de la mesa de Salomón, como último estertor de los sueños de las ambiciones frustradas de grandes hombres y mujeres que soñaban con restaurar la gloria de la Antigüedad, o lo que entendían ellos por esta (Meana, 1997: 42-44).

Así, ni la proclamación como emperador de Carlomagno resucitó el imperio romano ni la unión entre Constantinopla y Aquisgrán fue posible; tampoco se consiguió el restablecimiento del reino de los godos pretendida por Alfonso II y el mismo Teudán de la gloria de la antigua ciudad regia de Toledo. Tal proclamación no puede ser sino atribuida al propio cronista, puesto que pone esas palabras en la boca del fallecido y espectral Teudán. Un pasaje, de carácter tan sobrenatural, que hasta el propio Suero, hijo y ayudante de Leodegundo, le espeta que está escribiendo una historia muy extraña 
(Meana, 1997:47). No es el único episodio donde la fantasía se entremezcla con la realidad; para el pensamiento del eclesiástico los distintos credos y seres sobrenaturales son tan reales como lo fueron para sus mayores y como tal los

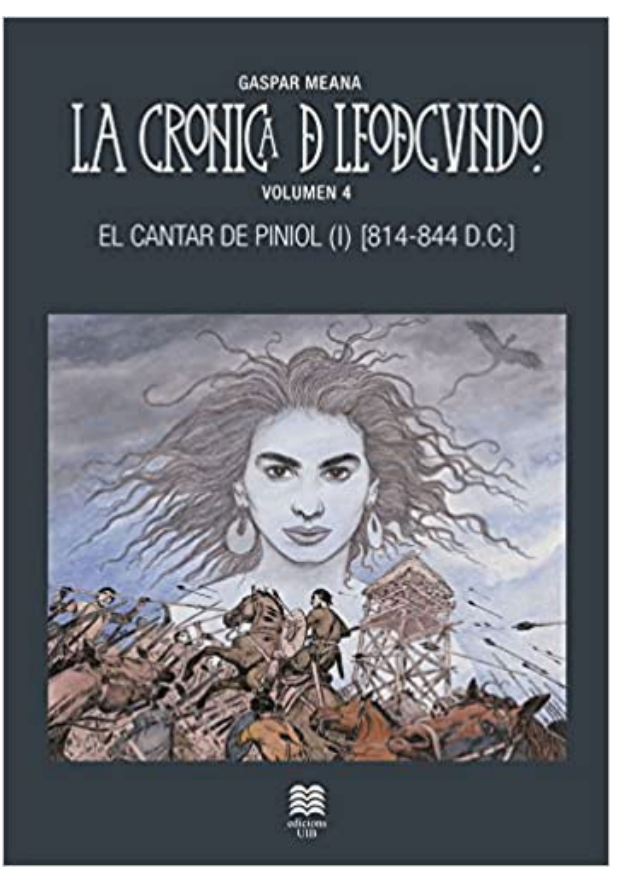

La Crónica de Leodegundo. El cantar de Piniol (I) (814-844 d. C.), Gaspar Meana caracteriza poblando su relato.

Esta es quizás la mayor moraleja de todo el cómic: cómo la historia acaba destruyendo toda empresa o designio humano a través de la incompetencia de sus descendientes; la importancia de saber ser flexible ante las vicisitudes vitales que se sufren y la capacidad de adaptarse a todo, sacrificando la integridad si es preciso. La rectitud y lealtad de Liuva le granjearon su exilio; la ambición y tentación del poder para Teudán se respondió con la crucifixión; la soberbia de Piniol al no postrarse ante la nueva realidad política del reino, su ejecución.

Pero, por encima de todo, existe una fijación con la importancia de la familia, que suele ser la que sufre los castigos por los actos de sus patriarcas y que suelen terminar en su encarcelamiento y exterminio. No es casualidad que no es sino hasta que se producen las decisiones más importantes de sus vidas que Liuva se lamenta por su hijo mientras parte al exilio, Teudán entiende que lo más importante no fue nunca perseguir fantasmas del pasado ni el poder de un trono o que Piniol que ni toda su piedad, soberbia y orgullo salvará a su familia. Casos similares son también mostrados en forma de las familias de los distintos imperios. Cómo el exceso, en cualquiera de sus formas, lleva a la decadencia y caída de dinastías.

Existen dos tipos de acontecimientos en el relato de Leodegundo. Aquellos que son los principales focos de interés que Meana desea exponer y los otros acontecimientos, secundarios, que pertenecen al anecdotario de las crónicas y libros de los cuales no siente que deba o esté suficientemente preparado para cuestionar pero que dan color y sensación de realidad al conjunto del relato.

Resumiendo, y mucho, se puede identificar que la tesis principal y motivo por el cual el monje comienza a redactar la historia oral de su familia es que la orientación política del reino fue cambiada dramáticamente por un golpe de estado por parte de Ramiro I contra el que podría ser el verdadero heredero de Alfonso II, Nepociano, que resultó en la caída en desgracia de su linaje. Esta afirmación sobre la usurpación del trono a través del cómic se adelantó en 6 años a la que Armando Besga (2003) realizó a principios del siglo XXI, un año después de la publicación del volumen XX donde Nepociano es nombrado comes palatii y de facto heredero al trono (Meana, 1997: 44-45).

A partir de aquí, y ya en la recta final de la serie, se justifica el programa propagandístico ramirense cuyo culmen es la construcción de Santa María 
del Naranco, cuya función original tiñe con una oscura luz la visión del hermoso monumento declarado como Patrimonio de la Humanidad por la UNESCO, y la necesidad de su nieto, Alfonso III, de justificar la legitimación al trono mediante un proyecto cronístico que debía sustituir la documentación existente hasta el momento, conviniendo en la pérdida de la que debió escribirse en época de Alfonso II destruyendo el conocimiento del largo reinado de este último para siempre.

Mientras que la edición original en bable era parca en detallar y mostrar claramente muchos de las cuestiones y propuestas a los lectores no familiarizados con la historia del mundo Mediterráneo altomedieval, la segunda edición permitió al autor centrarse en la creación de una serie de anexos con decenas de páginas que le permite explicar y justificar, de un modo académico como nunca se ha podido ver en ningún otro cómic del género, el porqué de algunas viñetas.

En cierta manera, Gaspar Meana esgrime un cómic de los derrotados por la historia oficial relatada por los vencedores. Leodegundo, al transformar el relato oral en uno escrito, está salvando del olvido gran parte de la memoria familiar $y$, mediante la materialización de la palabra, permite que su verdad sea transmitida a quien esté dispuesto a leer. En términos actuales, no es tan descabellado pensar que La Crónica de Leodegundo se adelanta, de manera no pretendida, al fenómeno de las publicaciones sobre la memoria histórica en el cómic. Al fin y al cabo cumple los mismos parámetros que rigen una parte del género de la historia contemporánea en el cómic español del siglo XXI: autor/a recoge testimonios y recuerdos familiares (propios o ajenos) y los convierte en un relato ficcionado y estructurado en viñetas para divulgar la verdad de un pasado olvidado por los libros de historia. Una manipulación que cincela la memoria de la propia sociedad haciéndola ignorante de su propio pasado, de unos hechos denunciables y reprobables, de la injusticia impune cometida.

\section{3. ¿Cuándo se realizó?}

El contexto temporal de la génesis de la serie no podría ser más adecuado y coincidente con una serie de publicaciones que sacudirán los años 90 como no había ocurrido desde los 60. Si en esta última década el sector de la industria editorial dedicada a la temática histórica se había hundido irremediablemente ante el desgaste de las fórmulas comerciales que habían exprimido hasta agotar el mercado, la década de los 70 no ofrecerá mejores perspectivas pese al notable trabajo de Antonio Hernández Palacios y las dos colecciones publicadas en la primera mitad de los 80: Grandes héroes, procedente de Francia, e Imágenes de la historia, nacional. La irrupción de cómics extranjeros con narrativas que abandonaban la didáctica en sus viñetas a favor de la calidad y fluidez de los guiones y un estilo gráfico más refinado y espectacular comenzó a ser cada vez más palpable.

Los 90, desde un punto de vista del cómic de historia, es una década clave en el que el tebeo de autor, publicaciones de álbumes y novelas gráficas ajenas 
a colecciones temáticas, comienzan realmente a destacar, confirmando la nueva tendencia de las formas de aproximar al lector a la historia mediante viñetas. Protagonistas de la historia, Relatos del Nuevo Mundo, cabeceras que nacieron por influjo del gran evento del quinto centenario del descubrimiento de América por Cristóbal Colón, marcaron que a partir de ahora las colecciones y títulos independientes serían mayormente fomentadas, si acaso, bajo los paraguas de los grandes eventos conmemorativos durante los siguientes 30 años. De manera paralela fueron surgiendo, cada uno en su contexto independiente y sin ningún tipo de influencia entre ellos, un reducido número de autores especializados en la historieta histórica desde las geografías de Asturias, Málaga y el área catalana.

A Gaspar Meana le siguieron rápidamente desde el sur Esteban Alcántara Alcaide y un conjunto de guionistas que trabajarán estrechamente con un dibujante, Oriol Garcia i Quera. Afincados en sus territorios de origen, estos serán los principales escenarios de una serie de publicaciones que narran las

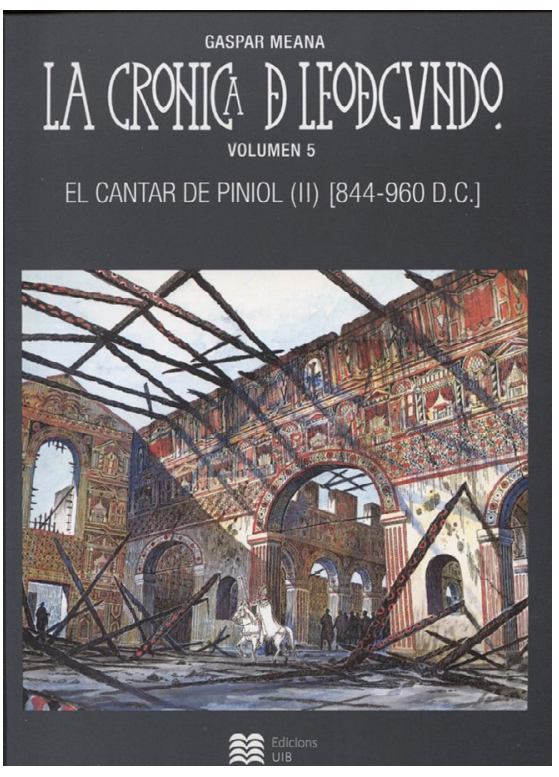

La Crónica de Leodegundo. El cantar de Piniol (II) (844-960 d. C.) Gaspar Meana historias locales de estos contextos geográficos. Así, si La Crónica de Leodegundo no fuera suficiente, Gaspar Meana seguiría cumpliendo con otros trabajos gráficos con capacidad suficiente como para publicar en 2001 La infanta, el pirata y el niño. El último año de la vieja Gijón (1395). Desde el sur Esteban Alcántara con sus trabajos centrados en la conquista cristiana de Málaga y posteriormente la aportación y situación de la capital de la Costa del Sol ante la guerra de la independencia. Y desde Cataluña, bajo los lápices de Oriol Garcia, veía la luz la colección Temps d'espases, centrada en diversos episodios enmarcados en la Catalonia Vella que profundizaba en el apartado narrativo más que didáctico, pese a que sigue estando ahí.

A partir de estos autores, se inaugura un periodo donde el género histórico se convierte completamente en un producto editorial independiente y goza de autonomía propia como lectura de consumo, generalmente bajo la consideración de novela gráfica. No nos quedaríamos cortos al decir que el surgimiento de estos tres dibujantes, de estos autores de cómic, marcan la aparición de un nuevo tipo de movimiento autónomo y completamente independiente de proyectos editoriales tales como las colecciones temáticas de historia.

\section{4. ¿Dónde?}

Un título que recoge buena parte de la historia del reino de Asturias difícilmente podría haber surgido en un lugar que no fuera desde el propio Principado. Fuera de cualquier significación identitaria regionalista, lo cierto es que existe una fuerte relación personal entre la temática de los tebeos de 
historia independientes de cualquier colección tematizada y la producción de un autor. Ya hemos recalcado anteriormente la existencia de los considerados como cronistas en cómic, donde creaban síntesis de la historia local o regional de sus tierras de origen, una característica que es localizable posteriormente en otros títulos y que marcan decisivamente el inicio de las génesis de esas obras.

En el caso asturiano existe un condicionante sine qua non Meana nunca habría visto publicada su gran serie altomedievalista. Probablemente tampoco hubiera sido viable hoy día por la poca capacidad de apuesta de las editoriales en un proyecto semejante; a día de hoy sigue siendo la serie moderna de cómics de historia más longeva de España. La solución vino de la mano de una subvención para fomentar y divulgar el bable entre los catálogos de las editoriales asturianas: publicaciones que venían amortizadas incluso mucho antes de que el primer ejemplar llegase a ser situado en las estanterías de las tiendas. No es de extrañarnos que, ante un tipo de producto que las propias editoriales no sabían bien cómo sobrellevar al carecer de tradición e intención comercial (Rodríguez, 2002: 55), podemos entender que apenas meses después de su término todas las copias no vendidas de la obra fueran destruidas por la editorial Llibros del Pexe (Meana, 2014: 242).

La exigencia de ser editada en bable se ve además señalada en las hojas de créditos de los primeros álbumes, donde se pone de manifiesto que el guion fue originalmente escrito en castellano y subsecuentemente traducido al bable. Su publicación en semejantes condiciones limitó por mucho sus ya reducidas posibilidades comerciales al área del Principado de Asturias, pero no así que fuera reconocido dentro y fuera de sus fronteras por especialistas y amantes del género.

\section{5. ¿Cómo se hizo?}

Meana comenzó su trabajo siguiendo el consejo de que debía trabajar utilizando la plumilla (Meana, 2014:225). Esto le impidió poder dar rienda suelta a toda su habilidad como dibujante y, tras el primer Cantar, desechó el consejo para adoptar otras técnicas más fáciles para él y eso se notó en el apartado gráfico, donde la calidad de los trazos y los detalles se elevó ridículamente hasta altas cotas de detalles en las recreaciones de los monumentos.

Desde un punto de vista material, La Crónica de Leodegundo fue publicada siguiendo modelos procedentes del mercado franco-belga, esto es, en formato álbum con unas medidas de $21 \mathrm{~cm}$ de base por $28 \mathrm{~cm}$ de altura, lo que la hace un mayor tamaño que el clásico comic-book norteamericano de $17 \times 26 \mathrm{~cm}$. Cada número tenía 48 páginas en blanco y negro que, a veces, dependiendo de si incluía anexos, aumentaba hasta las 54. La tapa blanda o rústica ha sido hasta ahora el único formato que ha tenido, tanto en su primera como segunda edición. Su precio de venta al público sufrió variaciones, que fluctuó según el volumen, y experimentó la conversión y el aumento generalizado de los precios que supuso la introducción del euro en nuestro país. En términos generales, y sin adaptar el valor a lo que sería hoy la edición de cómic, el PVP basculó entre los 8 a los $12 €$. 


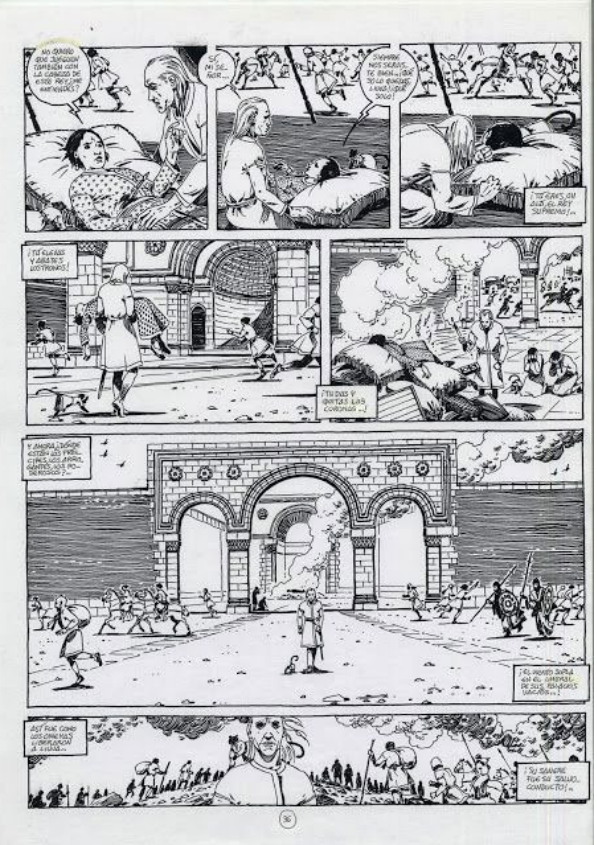

La Crónica de Leodegundo, Gaspar Meana

Como se ha apuntado anteriormente, la editorial de la Universitat de les Illes Balears asumió el desafío de reeditar la obra y lo realizó mediante la recopilación en forma de integrales de cada uno de los cantares. La comercialización por parte de la UIB constó en 5 volúmenes con un PVP de 28,5€ cada uno, excepto el volumen 2 que fue de 27,08 , y aumentó ligeramente su tamaño a $23 \times 31 \mathrm{~cm}$. Pese a que se continuó con la edición rústica, se ofreció una novedad importante respecto a la edición original: parte del momento cumbre de la obra fue coloreado para la ocasión.

El plato fuerte y principal atractivo de la edición actual consiste en el añadido, mediante cartas manuscritas del propio autor, de anexos documentales, en torno a 60 páginas de longitud, donde se hace presente bibliografía especializada y se ofrecen explicaciones, ilustraciones y justificaciones a lo desarrollado en las viñetas e incluso contenidos que no hubieran podido entrar de manera orgánica en la trama. Tales textos no hacen sino dar testimonio del virtuosismo del autor en materia historiográfica y le hace destacar con fuerza entre la constelación de autores de cómic de historia.

El interior de las páginas se destaca por la poderosa fuerza visual de las bellas recreaciones del pasado. El ritmo de su lectura no es como el del resto de cómics al uso, este requiere un ritmo mucho más pausado por la sobriedad de la narrativa y porque, como señala Faustino Rodríguez, la propia ambientación histórica forma parte de la narración en sí misma (2002: 65). Si un lector «devorase» las páginas como un cómic mainstream o comercial, se estaría perdiendo gran contenido histórico que sutilmente, sin hacer alarde ni resaltar puerilmente en la trama, está presente en las viñetas. Un breve ejemplo de la sofisticación desplegada en los detalles: en el volumen XVI hay un breve vistazo del templo romano de Córdoba mientras los personajes pasean a su lado sin reaccionar a la presencia de tal insigne y por entonces ya amortizado edificio (Meana, 2000: 19); una muestra de cómo el tiempo y los cambios sociales han desdibujado y transformado espacios urbanos tan importantes durante el periodo altoimperial (Rueda, 2015-2016: 154-155).

Y un último detalle no usualmente percibido, pero realmente notable: el trabajo de Leodegundo comienza y acaba en el 960 d. C. Una cartela nos informa de esto y, además, cada volumen tiene adjudicado en su título una cronología que da cuenta de la datación de los hechos incluidos en su interior, como si siguiera las anotaciones de un archivero. Nuestro narrador se encuentra sumamente preocupado por las señales del inminente juicio final, pero resulta extraño que, quedando 40 años para el año mil, tales inquietudes lo atormenten hasta tal punto de comenzar a redactar su crónica con tanta 
premura, vehemencia y poco descanso hasta el punto de causarle la muerte. Esto es porque, pese a que es el año 960 para nosotros, según el cómputo de la era hispánica que añade 38 años al calendario de la era cristiana (Cappelli, 1988: 6), el personaje creería estar en el año 998 d.C., literalmente a las puertas de la parusía.

\section{6. ¿Para qué o por qué?}

¿Qué sentido tiene la producción artística? Desde luego no fue una perspectiva lucrativa la que le llevó durante 16 años a entregarse a la creación del cómic (Rodríguez, 2002: 60). A raíz de las distintas declaraciones en entrevistas, es posible encontrar las razones: por un lado, dar salida a las inquietudes creativas e ilusiones que todo autor guarda dentro, lo que le llevó a hacer una historia del reino de Asturias desde la óptica asturiana y darle la importancia que quizás no es percibida (Rodríguez, 2002: 61). Por otro, él quería transmitir la importancia del conocimiento de la Historia, pues el bagaje cultural que tenemos por nacimiento determina en buena medida el destino que se tiene en la vida (Meana, 2014: 223).

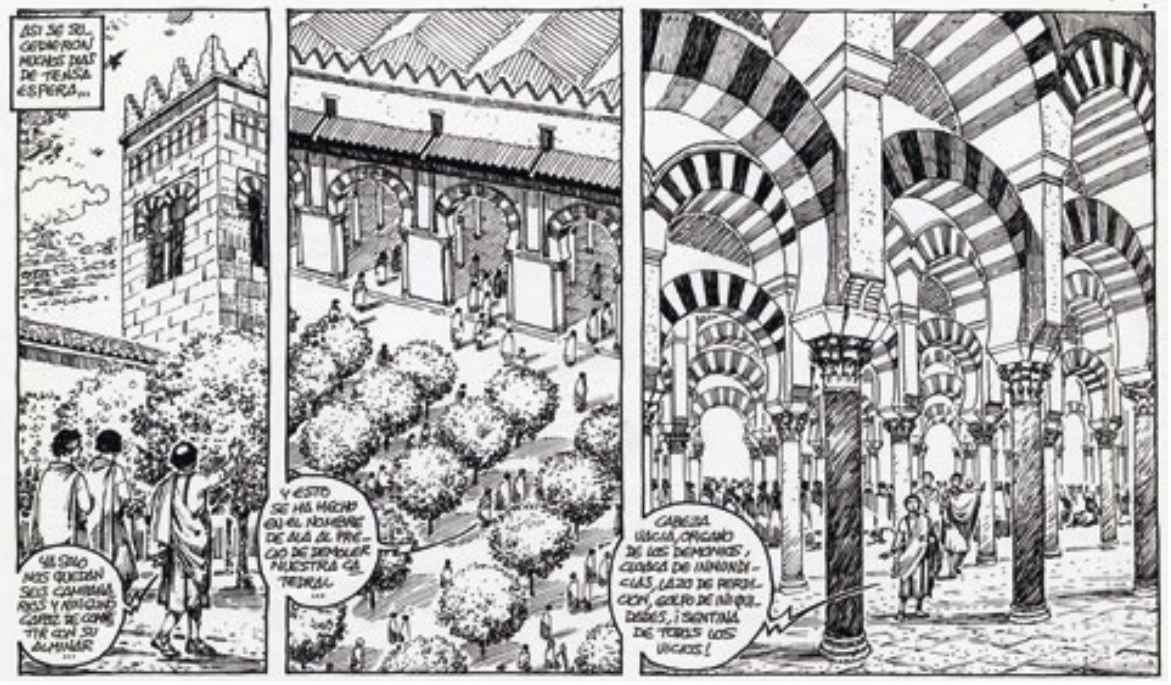

La Crónica de Leodegundo, Gaspar Meana

Todo esto se junta con sus propias reflexiones maduradas en base a su pasión por la historia y la lectura y consulta de fuentes que le hicieron darse cuenta de que la historia del reino de Asturias no era como se venía contando. Su intención no solo es entretener, es también plantear, hacer pensar al lector, que la historia misma a veces puede ser sencillamente ficción.

\section{Conclusiones}

Pensar en el reino de Asturias a través del cómic es tener que pensar inevitablemente en La Crónica de Leodegundo. Y pensar en historieta histórica española moderna debería tener asociado el nombre de Gaspar Meana, 
como el tebeo clásico tiene a Victor Mora o Manuel Gago como referentes. No ha habido mayor proyecto ni mayores esfuerzos invertidos en una saga de historieta histórica en nuestro país semejantes a los realizados a lo largo de 16 años, y la reedición de esta obra magna a cargo de una universidad no solo es merecida, sino señal de las posibilidades que el medio puede ofrecer.

Desafortunadamente, la incomprensión y falta de visión de los editores de cómics, el desatino de su puesta en circulación, terriblemente limitado a un área peninsular por su idioma y la destrucción del estocaje no jugaron en su momento a favor de una mayor difusión. Meana es un gigante de la documentación histórica y, como cualquier gigante, no podía crear sino algo monumental, ciclópeo; tan grande, que resulta harto difícil realizar una síntesis equilibrada sobre los contenidos de la misma; no en vano, pese a que vivimos en una nueva edad de oro de la investigación estudios sobre cómic, esta gran saga continúa siendo un terreno mayormente ignoto al no poder ser abordada sin un trabajo exigente que pocos académicos podrían estar dispuestos a querer realizar.

Y es que algo tan increíble no vino sin un terrible precio a pagar. Como el propio autor ha confesado, él ya no está interesado en realizar más cómics y ha centrado sus esfuerzos en realizar una biografía sobre Alfonso ll aún por ser publicada (Meana, 2014: 223). Esto no ha significado que no hayamos podido recibir ese pequeño cómic con motivo de las conmemoraciones de la batalla de Covadonga titulado El reino que nació en Asturias.

Para terminar, tenemos que reflexionar sobre las cuestiones lanzadas por Sergi Vich. ¿̇Es un cómic de ficción con base histórica o una tesis histórica expresada mediante viñetas? La respuesta no puede decantarse en uno de ambos extremos, sino encontrarse en el centro de la escala de grises. Indudablemente hay una intencionalidad de exponer una serie de puntos en su discurso a lo largo del transcurso de las viñetas, pero lo hace hilvanando al mismo tiempo un cómic con una trama y unos personajes que, aunque con base histórica, son ficciones de los mismos. Por tanto, no es descabellado considerar que estamos ante una (o varias) tesis histórica en el interior de un cómic de ficción.

No consideramos una mejor manera para concluir que citar y suscribir todas y cada una de las palabras que Faustino Rodríguez de dicase para sentenciar a La Crónica de Leodegundo en su libro La Historieta Asturiana (2002: 66): «Obra maestra que perdurará en el tiempo, que engrandecerá con su difusión a este medio de expresión, a este ARTE, conocido por los nombres de Historieta o Cómic̀. 


\section{Bibliografía}

Besga Marroquín, Armando (2003), «El rey Nepociano de Asturias, monarca legítimo y vasco», Letras de Deusto, 33 (101), 9-41.

Borge Cordovilla, Francisco José (2017), «Santa María de Naranco de pabellón profano a palacio sagrado. Hipótesis de interpretación en función del análisis simbólico y arquitectónico», Anvario de la Sociedad Protectora de la Balesquida, 2, 159-179.

Cappelu, Adriano (1988), Cronologia, cronografia e calendario perpetuo. Dal principio dell'era cristiana ai nostri giorni, Milán, Editore Ulrico Hoepli.

Díaz González, María del Mar (2021), "Crónicas y gestas: la historia de Asturias desde la perspectiva comicgráfica»), en Dibujando historias. El cómic más allá de la imagen, coords. Julio A. Gracia Lana, Ana Asión Suñer y Laura Ruiz Cantera, Zaragoza, Servicio de Prensas de la Universidad de Zaragoza, pp. 189-201.

Domínguez Prats, Pilar (2011), "Comunicación oral, Memoria e Historiay), en Los medios de transmisión de información, ed. Enrique Pérez Herrero, Las Palmas, Gobierno de Canarias, pp. 33-42.

Fernández Menéndez, Mercedes (1999), Asturias: imágenes de historieta y realidades regionales, Oviedo, Servicio de Publicaciones de la Universidad de Oviedo.

Galván Frelle, Fernando (2008), «La imagen de la Edad Media en el cómic: entre la fantasía, el mito y la realidad», Revista de Poética Medieval, 21, 125173.
García de Castro Valdés, César (2003), «Notas sobre teología política en el reino de Asturias: la inscripción del altar de Sta. María del Naranco (Oviedo) y el testamento de Alfonso |l», Arqueología y territorio medieval, 1 (10), pp. 137-170. DOI: https://doi. org/10.17561/aytm.v10i1.1566

Gasca, Luis y Asier Mensuro (2014), La pintura en el cómic, Madrid, Ediciones Cátedra.

Hernando Morejón, Jacobo (2018), «Tratamiento de la historia en el tebeol, en Nuevas visiones sobre el cómic. Un enfoque multidisciplinar, Zaragoza, Prensas de la Universidad de Zaragoza, coords. Julio A. Gracia Lana y Ana Asión Suñer, Zaragoza, Prensas de la Universidad de Zaragoza, pp. 133-138.

Hernando Morejón, Jacobo (2021), "Cristianos, musulmanes y judíos. Presencia de la España medieval de las tres culturas en el cómicy, en Dibujando historias. El cómic más allá de la imagen, coords. Julio A. Gracia Lana y Ana Asión Suñer y Laura Ruiz Cantera, Zaragoza, Prensas de la Universidad de Zaragoza, pp. 485-492.

Meana González, Gaspar (1991-2006), La Crónica de Leodegundo, Gijón, Llibros del Pexe.

Meana González, Gaspar (1997), La Crónica de Leodegundo XV. Nel país de los Mairús (814-817 d.C.), Gijón, Llibros del Pexe.

Meana González, Gaspar (2000), La Crónica de Leodegundo XVI. Revolución (817-818 d.C.), Gijón, Llibros del Pexe.

Meana González, Gaspar (2013-2017), La Crónica de Leodegundo, Palma de Mallorca, Edicions UIB.

Meana González, Gaspar (2014), La Crónica de Leodegundo Volumen 3. 
El Cantar de Teudán (II) [800-814 d.C.], Rodríguez Arbesú, Faustino (2002), La Palma de Mallorca, Edicions UIB. Historieta Asturiana, Gijón, Grupo El Meana González, Gaspar (2016), La Wendigo.

Crónica de Leodegundo Volumen 5. RuedA Olvo, Francisco José (2015-2016). El Cantar de Piniol (II) [814-960 d.C.], Palma de Mallorca, Edicions UIB. «El Templo Romano de Córdoba. Meana González, Gaspar (2018), El arqueología e historia, 22, 151-160. reino que nació en Asturias, Oviedo, VICH, Sergi (1997), La historia en los Gobierno del Principado de Asturias. cómics, Barcelona, Glénat.

Petruccl, Armando (2002), La ciencia VICH, Sergi (2013), «La Edad Media vista de la escritura. Primera lección de por el cómicl, Arqueología, historia y paleografía, Buenos Aires, Fondo de viajes sobre el mundo medieval, 47, Cultura Económica de Argentina. 34-45. 
Hernando Morejón, Jacobo, «30 años de la Crónica de Leodegundo: aproximación a la gran saga de la historieta histórica española», Storyca 3 (2021), pp. 79-96.

https://doi.org/10.51863/Storyca.2021. Hernando

\section{Resumen}

En 1991 vio la fecha de venta al público el inicio de una de las más importantes sagas de la historieta histórica española. Marcada por una palpable consulta de estudios y fuentes históricas, convirtió en su autor, Gaspar Meana, en uno de los mejores y más prolífico autor de tebeos del género en España. Originalmente, una serie de desatinos a la hora de su comercialización le hizo difícil su difusión en la mayoría del público lector de historieta español que ahora ve una segunda oportunidad gracias a la reedición por una universidad española, garante de la soberbia calidad del título. Pese a que los amantes del género co-nocen o saben de su existencia, los estudios sobre cómic no han podido sino hacer apro-ximaciones ligeras a la obra precisamente por su gran extensión. Nuestro estudio pretende recopilar comentarios de la crítica de cómic acerca de La Crónica de Leodegundo en el $30 .^{\circ}$ aniversario de su publicación y profundizar en ella mediante una aproximación al estudio de sus páginas como un documento desde la óptica de la corriente de la Historia de la Cultura Escrita.

\section{Abstract}

In 1991 the release date to the public saw the beginning of one of the most important sa-gas of the Spanish historical comic strip. Distinguished by an obvious consultation of studies and historical sources, its author, Gaspar Meana, became one of the best and the most prolific author of comics of the genre in Spain. Originally, a series of mistakes at the time of its commercialization made it difficult for it to be known among the majority of the Spanish comic reading public. Nowadays it sees a second chance thanks to the reprinting by a Spanish university, guarantor of the superb

\section{Palabras clave}

Alta Edad Media Recreación Reino de Asturias

\section{KeyWords}

Early Middle Ages Reenactment Kingdom of Asturias 
quality of the title. Despite the fact that lovers of the genre know or they are aware of its existence, studies on comics have only been able to make light approaches to the work precisely because of its great extension. Our study aims to compile commentary from comic book critics about La Crónica de Leodegundo on the 30th anniversary of its publication and to deepen it through an approach to the study of its pages as a document from the perspective of the current of the History of Written Culture. 